\title{
Gut Microbiota in Neurological Disorders
}

\author{
Marta Grochowska $^{1}$ (1) $\cdot$ Tomasz Laskus $^{2} \cdot$ Marek Radkowski $^{1}$
}

Received: 12 February 2019 / Accepted: 12 September 2019 / Published online: 1 October 2019

(c) The Author(s) 2019

\begin{abstract}
The incidence of neurological disorders such as multiple sclerosis (MS), Alzheimer's disease (AD) and Parkinson's disease (PD) is increasing throughout the world, but their pathogenesis remains unclear and successful treatment remains elusive. Bidirectional communications between the central nervous system and gut microbiota may play some role in the pathogenesis of the above disorders. Up to a thousand bacterial species reside in human intestine; they colonize the gut shortly after birth and remain for life. Numerous studies point to the role of microbiota composition in the development, course and treatment of MS, AD and PD.
\end{abstract}

Keywords Gut $\cdot$ Microbiota $\cdot$ Neurological disorders

\section{Introduction}

The purpose of this review is to summarize the current knowledge about the role of gut microbiota composition in the development, course, and prognosis of selected neurological diseases. Global incidence of a number of common neurological disorders is rapidly increasing (Bengmark 2013) and consumption of industrially manipulated meat, dairy and wheat products, which lead to changes in gut microbiota, could be contributing factors (Bengmark 2007). Understanding the effects of diet on human gut microbiota is therefore of major importance (Kau et al. 2011).

The central nervous system (CNS) and the gut microbiota interact in a bidirectional manner, e.g. the CNS modulates gut functioning in response to psychological and physical stressors affecting motility, secretion and immune reactivity (Mayer 2000), whereas changes in gut microbiota may cause behavioural and neurochemical changes (Bravo et al. 2011). Consequently, the term microbiota-gut-brain (MGB) axis was proposed to stress the importance of these interactions (Collins et al. 2012; Rhee et al. 2009). the MGB regulates the gastrointestinal (GI) tract and CNS (Dinan et al. 2014) by

Marta Grochowska

marta.grochowska@wum.edu.pl

1 Department of Immunopathology of Infectious and Parasitic Diseases, Medical University of Warsaw, Warsaw, Poland

2 Department of Adult Infectious Diseases, Medical University of Warsaw, Warsaw, Poland way of the vagus nerve, hypothalamic-pituitary-adrenal axis and various cytokines (Dinan et al. 2014; Jones et al. 2006).

Up to a thousand bacterial species live in human intestine (Mazmanian et al. 2008), and as many as $10^{11}$ bacteria cells can be found in $1 \mathrm{~g}$ of colon contents (Guarner and Malagelada 2003). This particular ecosystem includes not only bacteria, which are often unculturable (Xu et al. 2007), but also viruses, protozoa, archae and fungi (Dinan and Cryan 2012). Commensal bacteria colonize the human intestine shortly after birth and remain there for life (Foster and McVey Neufeld 2013). The most common phyla are Firmicutes and Bacteroidetes, which represent $70-75 \%$ of total microbiome defined as genetic material of all intestinal microbes. Other bacteria occurring in lower quantities are Proteobacteria, Actinobacteria, Fusobacteria and Verrucomicrobia (Eckburg et al. 2005). The microbiome composition is affected by diet, metabolism, age, geography, stress and antibiotic treatment (Foster and McVey Neufeld 2013). For example Bacteroides spp. dominate in people on long-term protein and animal fat diet, whereas Prevotella spp. dominate in those on carbohydrate diet (Wu et al. 2011).

Intestinal microbiota can modulate gut functioning, e.g. Bifidobacterium bifidum and Lactobacillus acidophilus promote motility (Rhee et al. 2009), whereas Escherichia species exert the opposite effect (Mazmanian et al. 2008; Rhee et al. 2009). Gut dysbiosis, which is defined as a major shift in microbial composition and function (Fond et al. 2015) can cause diarrhea or constipation (Rhee et al. 2009), but even small changes in the gut microbiota can provoke clinical 
symptoms (Bravo et al. 2012). Overall, microbiota composition is highly individualized and dynamic (Foster and McVey Neufeld 2013).

Intestinal mucosa, which represents a barrier between the internal and external environments, is subjected to stress (Haq et al. 2019). This barrier function is supported by diverse bacteria forming commensal microflora (Brown 2016). The intestinal mucosa is responsible for absorption of water, nutrients and gases, clearance of waste, maintenance of immunity and much more (Haussner et al. 2019). Intestinal mucosa, gut microbiota, immune cells in the mucosa and various products of epithelial origin are all components of the so called "gut barrier". If the integrity of the latter becomes compromised, leaky gut syndrome (LGS) ensues leading to systemic- and neuroinflammation and causing dysfunction in the cerebellum and hippocampus (Bengmark 2013; Daulatzai 2014; Farhadi et al. 2003). Importantly, patients with many CNS disorders were found to have increased intestinal permeability (Maes et al. 2012), and passing of harmful metabolites from intestine to blood can negatively affect the CNS (Julio-Pieper et al. 2014). Due to the damaged intestinal barrier, lipopolysaccharides (LPS), which are large molecules found in the outer membrane of Gram-negative bacteria, or even whole bacteria (Bengmark 2013), may enter the bloodstream causing endotoxemia and activating the immune system (Bengmark 2013). Intestinal permeability can be assessed by functional tests (sucrose test and cellobiose plus mannitol test), serological tests (antibodies to food antigens, autoantibodies), as well as by other markers (e.g. Zonulin serum levels) (Julio-Pieper et al. 2014).

While dysfunction in microbiota could play a role in the development of some neurological diseases, there is also mounting evidence that interventions restoring its health and intestinal barrier integrity can positively affect clinical course and symptoms (Julio-Pieper et al. 2014). The most common treatments targeting gut dysbiosis are probiotics, which are defined as living organisms providing health benefits to the host (Bravo et al. 2012), and antibiotics.

\section{Multiple Sclerosis}

Multiple sclerosis (MS) is the most common neurological disease of young adults in Europe and North America (Keegan and Noseworthy 2002). It is characterized by an autoimmune inflammatory process in which $\mathrm{CD} 4{ }^{+} \mathrm{CD} 25^{+}$ regulatory $\mathrm{T}$ (Treg) cells target brain and spinal cord cells leading to demyelination and axonal damage (Lavasani et al. 2010; Tremlett et al. 2016b).

A combination of genetic and environmental factors is likely to be involved in MS pathogenesis (Granieri et al. 2000), but none has been found to be essential (Tremlett and Waubant 2017). There is mounting evidence that an important role could be played by changes in the gut microbiome (Adamczyk-Sowa et al. 2017). While the specific mechanisms have not been elucidated as yet (Forbes et al. 2016), it seems that gut microbiota changes can cause a proinflammatory state resulting in CNS damage, the culmination of which is the development of MS (Adamczyk-Sowa et al. 2017; Rodriguez et al. 2016).

Bacteria species likely to be involved are Helicobacter, Clostridium and Enterococcus (Round and Mazmanian 2009). It was also shown that segmented filamentous bacteria can activate intestinal Th17 cells, which promote systemic autoimmunity and participate in immune response against intestinal pathogens (Atarashi et al. 2011). However, some findings point also to the ability of specific bacteria to provide anti-inflammatory effects (Adamczyk-Sowa et al. 2017). For example, Bacteroides fragilis' polysaccharide product was found to be able to modulate systemic Th1 and mucosal Treg cell responses in mice (Mazmanian et al. 2008).

Compared to healthy controls, MS patients have a decrease in the proportion of Faecalibacterium, Eubacterium rectale, Corynebacterium, Fusobacteria and an increase of Escherichia, Shigella, Clostridium, Firmicutes (Cantarel et al. 2015; Tremlett et al. 2016a, c). Decreased numbers of Faecalibacterium spp. and lower levels of its metabolite butyrate lead to decrease of Treg cells, antigenpresenting cells, and pro-inflammatory cytokines (Adamczyk-Sowa et al. 2017; Machiels et al. 2014). Several authors reported a decrease of such Bacteroides spp. as Bacteroides stercoris and Bacteroides coprocola in the gut microbiota of MS patients and a negative correlation between the number of Prevotella copri and the risk of MS development (Miyake et al. 2015).

Tremlett et al. (2016b) found no differences in immune markers such as the number of Th2, Th17 and Tregs cells between children with MS and healthy controls. However, abundance of gut microbiota correlated positively with Th17 in affected children, but not in controls, whereas Bacteroidetes spp. numbers correlated inversely with Th17. The abundance of Fusobacteria correlated positively with Tregs only in controls.

Some bacterial products could play a role in the communication between the gut and brain. For example, serum levels of Bactroidetes spp. metabolite lipid 654 were found to be significantly lower in MS patients than in healthy controls, and are even regarded by some as an MS biomarker (Farrokhi et al. 2013; Kleinewietfeld et al. 2013). Another example is Clostridium perfringens toxins B and D (Uzal et al. 2004), which are able to induce such symptoms as lack of movement coordination or blurred vision, which are similar to MS (Adamczyk-Sowa et al. 2017). In MS patients these toxins may cause inflammation of the retina 
by affecting the barrier veins or by binding to vascular system receptors (Barnett et al. 2009; Fennessey et al. 2012; Nagahama and Sakurai 1992). Toxins of C. perfringens are not detectable in healthy subjects (Adamczyk-Sowa et al. 2017; Murrell et al. 1986; Rumah et al. 2013).

Studies on the role of gut microbiota in experimental autoimmune encephalomyelitis (EAE), which is the most widely used animal model of MS, showed that oral treatment with ampicillin, vancomycin, neomycin, sulfate, and metronidazole can delay the onset and reduce the severity of the disease, decrease levels of pro-inflammatory cytokines and increase levels of interleukin (IL)-10 and IL-13 (OchoaReparaz et al. 2009).

Administration of probiotics (IRT5 containing Lactobacillus casei, Lactobacillus acidophilus, Lactobacillus reuteni, Bifidobacterium bifidum, and Streptococcus thermophilus) before the induction of EAE resulted in its delayed onset and milder course (Forbes et al. 2016; Kwon et al. 2013). In another experiment, treatment by probiotics containing Lactobacillus paracasei and L. plantarum suppressed the development of EAE and reduced severity of clinical symptoms while increasing the number of Treg cells in mesenteric lymph nodes, and increasing production of transforming growth factor $\beta 1$ and IL-27. Interestingly, this effect was not observed when the two bacteria species were administered separately (Forbes et al. 2016; Lavasani et al. 2010).

The effects of microbiota therapeutic interventions in humans have not been studied extensively. However, MS patients who underwent fecal microbiota transplantation showed amelioration of neurologic symptoms and improvement of life quality (Evrensel and Ceylan 2016), but these studies were too small to be conclusive. It should be stressed that unhealthy life style choices such as high consumption of salt, animal fat, carbohydrates and low physical activity negatively affect gut microbiota composition and metabolism leading to LGS and exacerbation of MS symptoms (Adamczyk-Sowa et al. 2017; Riccio and Rossano 2015).

\section{Alzheimer's Disease}

Alzheimer's disease (AD) is a common neurodegenerative disease of the elderly accounting for $60-80 \%$ of all dementia cases (Alzheimer's Association 2015; Hu et al. 2016). It is expected that the number of patients with dementia worldwide will double every 20 years reaching 115 millions in 2050 (Prince et al. 2013). AD is characterized by the accumulation in the cerebral cortex and other brain regions of misfolded amyloid- $\beta(A \beta)$ fibrils and oligomers, such as neurofibrillary tangles consisting of hyperphosphorylated tau protein (Mager et al. 2014). There is also evidence for the presence of neuroinflammation and prion-like pathology (Scheperjans 2016a), which are being intensively studied to identify potential causes (Tremlett et al. 2017). It is currently believed that both environmental and genetic factors are involved in the pathogenesis of $\mathrm{AD}$ (Hu et al. 2016).

Clearly, some role in the pathogenesis could be played by LGS, which causes increased permeability of blood-brain barrier (BBB), $A \beta$ accumulation in brain and inflammatory response (Hu et al. 2016). LPS, which elicit strong immune responses (Bengmark 2013) were found to be elevated in AD patients (Zhang et al. 2009), while in mice models LPS increases $A \beta$ levels in the brain (Jaeger et al. 2009) and causes severe memory loss (Kahn et al. 2012).

High-fat and/or high-calorie diet seems to be a risk factor for AD development (Eskelinen et al. 2008; Knight et al. 2014). Diet can affect gut microbiota in multiple ways; for example gluten and sugars stimulate systemic inflammation and consequently affect CNS functions (Hu et al. 2016). Such components of diet as deep-sea fish, nuts, and vegetable oils (Gu et al. 2010), which are all major dietary sources of Omega 3 polyunsaturated fatty acids ( $\omega$-3 PUFAs) can lower the risk of AD (Morris et al. 2003), and AD patients often demonstrate low levels of DHA (docosahexaenoic acid), which is one of the $\omega-3$ PUFAs. Importantly, gut microbiota is involved in the absorption and metabolism of $\omega$-3 PUFAs (Hu et al. 2016; Tully et al. 2003).

PUFAs include such important compounds as essential fatty acids (EFA), which are not synthetized by humans (Yehuda et al. 2005). EFA affect brain function and seem to be important for many brain disorders (Yehuda et al. 2005). Since EFA and PUFAs must be derived from food, they are capable of crossing the BBB. Decreased brain levels of EFA, especially in the cortex and hippocampus, which mediate learning and memory, were reported in $\mathrm{AD}$ patients, and this deficiency was likely due to the reduction in their ability to cross the BBB (Yehuda et al. 2005). Decreased brain EFA levels are likely to play a role in cognitive decline (Yehuda et al. 2002).

Fruits and vegetables lower the risk of AD probably by providing antioxidants and vitamins (Hughes et al. 2010). The same effect could be conferred by antioxidant polyphenols found in coffee, which reduce brain injury caused by oxidative stress (Hu et al. 2016). Accordingly, it was reported that drinking three to five cups daily decreases the risk of $\mathrm{AD}$ by $65 \%$ compared to drinking less than two cups per day (Eskelinen et al. 2009). Diet and specific nutrients seem to affect gut microbiota composition and influence the production and aggregation of amyloid proteins (Friedland 2015; Scott et al. 2013).

Amyloid- $\beta$ accumulation is the cornerstone feature of $\mathrm{AD}$, but the exact mechanisms behind this phenomenon are not fully understood (Cattaneo et al. 2017). Cognitively impaired patients with brain $\mathrm{A} \beta$ deposition were reported to have lower stool abundance of anti-inflammatory E. rectale and $B$. fragilis and higher abundance of pro-inflammatory 
Escherichia spp. and Shigella spp. when compared to cognitively impaired patients with no $\mathrm{A} \beta$ deposition or healthy controls (Cattaneo et al. 2017; Mancuso and Santangelo 2018). These differences could be reflected in the inflammatory state, as the first group was reported to have higher levels of pro-inflammatory cytokines (IL-6, CXCL2, NLRP3, and IL-1 $\beta$ ) and lower levels of anti-inflammatory IL-10 (Cattaneo et al. 2017).

Lactobacillus spp. and Bifidobacterium spp. can produce gamma-Aminobutyric acid (GABA) (Barrett et al. 2012) and may improve cognitive functioning of AD patients when used as probiotics. Post mortem studies of AD brains showed reduced GABA concentrations in many cortical and limbic regions (cingulate, amygdala and thalamus) (Lanctot et al. 2004).

Cognitive decline is the key feature of $\mathrm{AD}$ (Archer et al. 2011; Carlino et al. 2013) and it has been found that it impairs life quality much more than other behavioural or even psychotic symptoms (Nuechterlein et al. 2011). Cognitive disturbances may be associated with altered activity of various growth factors, including neurotrophins such as brain-derived neurotrophic factor (BDNF) (Carlino et al. 2013). BDNF is involved in such processes as neuronal development and differentiation, as well as synaptic plasticity (Carlino et al. 2013) and its expression may be modulated by gut microbiota: it was reported that specific pathogen-free mice have higher BDNF mRNA levels in the hippocampus and amygdala compared to germ-free animals (Diaz Heijtz et al. 2011). Post mortem studies of AD brains showed a 30\% decrease in the amount of proBDNF compared to controls and this decrease was as high as $40 \%$ in end-stage patients (Michalski and Fahnestock 2003). BDNF serum levels in $\mathrm{AD}$ patients are lower than in subjects with other types of dementia or healthy controls (Carlino et al. 2013; Nieto et al. 2013). However, while serum levels of BDNF are easy measured, they are neither predictive of AD development nor correlate with Functional Assessment Staging (Laske et al. 2006; Yasutake et al. 2006).

There is some evidence that bacteria and bacterial endotoxins may be directly involved in the pathogenesis of $\mathrm{AD}$ (Asti and Gioglio 2014). Thus, it was reported that infusion of LPS into the fourth ventricle in rats causes brain changes similar to those found in AD patients (Asti and Gioglio 2014). In human studies, transcriptionally active Chlamydia pneumoniae was detected in autopsy brains tissue of $\mathrm{AD}$ patients (Balin et al. 1998) and Spirochaetes (Borrelia burgdorferi, Treponema pallidum) were found in cerebrospinal fluid and the cerebral cortex of patients with general paresis suggesting that these bacteria might play a role in slowly progressive dementia, cortical atrophy, and local amyloidosis (Asti and Gioglio 2014; Miklossy 2011). Furthermore, serum IgG and IgA against Helicobacter pylori were reported to be more common in AD patients (Malaguarnera et al. 2004), while Escherichia coli endotoxin may facilitate formation of $\mathrm{A} \beta$ fibrils in vitro (Asti and Gioglio 2014).

The gut microbiota may influence $\mathrm{AD}$ in various ways. Most notably, paucity of gut bacteria may contribute to the development of this disease as a negative correlation was observed between the incidence of $\mathrm{AD}$ and microbiota diversity. In the developed countries with high level of hygiene and consequently decreased microbial diversity, the incidence of AD is increasing (Fox et al. 2013). Also bacterial products such as amyloids and LPS, may accumulate in the blood and brain and contribute to the pathological features of AD (Zhao and Lukiw 2015). Some bacteria species, e.g. Firmicutes, Bacteroidetes, Proteobacteria, produce amyloids inducing pro-inflammatory IL-17A and IL-22 cytokines, which are linked to chronic inflammatory diseases, including AD (Hill and Lukiw 2015; Zhang et al. 2013). Further, gut microbiota changes may cause activation of pro-inflammatory cytokines and consequently increase intestinal permeability (Bekkering et al. 2013), especially in forms of $\mathrm{AD}$ characterized by pronounced learning problems and memory loss (Hu et al. 2016). Finally, the gut microbiota is responsible for the production of such vitamins as B12, which reduces the risk of dementia (Hu et al. 2016) and $\mathrm{AD}$ (Quadri et al. 2004).

Interestingly, administration of Bifidobacterium lactis HN019 decreases the levels of pro-inflammatory cytokines IL-5, IL-6, IL-1 $\beta$, IL-8 and tumor necrosis factor $\alpha$ (Rincon et al. 2014; Wang et al. 2015). It was also shown that probiotics are able to increase the levels of anti-inflammatory cells (total, helper $\mathrm{CD} 4^{+}$, and activated $\mathrm{CD} 4^{+} \mathrm{CD} 25^{+} \mathrm{T}$ cells in the peripheral circulation) (Gill et al. 2001; Pistollato et al. 2016).

\section{Parkinson's Disease}

The mean time from diagnosis to death in Parkinson's disease (PD), the second most common neurodegenerative disorder of elderly, is 15 years (Forsyth et al. 2011; Katzenschlager et al. 2008; Lees et al. 2009). PD prevalence is approximately $0.4 \%$ and the number of cases is predicted to double by the year 2040 (Adams-Carr et al. 2016; Kowal et al. 2013). The median age for the onset of PD is 60 years and the ensuing disabilities are characterized by motor and non-motor symptoms including dementia, which is lifethreatening condition (Hobson et al. 2010; Marras and Lang 2008). The majority of PD cases are diagnosed on the basis of neurological symptoms such as tremor, bradykinesia, rigidity, when a significant proportion of neurons within the substantia nigra is already damaged (Adams-Carr et al. 2016; Forsyth et al. 2011).

The key feature of PD is the presence of neuronal inclusions (Lewy Bodies or Lewy neurites) consisting of 
aggregated and phosphorylated $\alpha$-synuclein (Braak and Del Tredici 2008). While the cause of PD remains unknown, the GI tract is the source of many toxins affecting the CNS (Julio-Pieper et al. 2014) and interacts with the brain by the dorsal motor nucleus of the vagus nerve. The latter nucleus seems to be the earliest site of Lewy Bodies expression in the course of the disease (Braak and Del Tredici 2008; Forsyth et al. 2011). Several studies reported on the presence of Lewy Bodies in the esophagus and colon (Kupsky et al. 1987; Lebouvier et al. 2008, 2010; Qualman et al. 1984), which suggests that GI tract is somehow involved in the pathogenesis of PD.

Non-motor symptoms, including mood and cognitive impairment, sleep disorders, sensory disruption and GI dysfunction (Postuma et al. 2012), are common in PD and can severely impact patients' quality of life (Gallagher et al. 2010). The second most common non-motor symptom after anosmia is constipation affecting $50 \%$ of patients. It is also a strong risk factor for PD (Adams-Carr et al. 2016). Moreover, functional and structural changes in GI tissues, such as $\alpha$-synuclein accumulation in the enteric nervous system (ENS) have been described in PD patients (Visanji et al. 2015). The ENS is responsible for normal gut functioning and represents a way by which commensal bacteria regulate many physiological functions, including intestinal motility (Kunze et al. 2009).

Gut microbiota abnormalities are common in PD patients and their relation to brain dysfunction is being intensively investigated (Scheperjans 2016b). In three different studies of fecal microbiota composition there was a decreased representation of bacteria Prevotellaceae, Coprococcus, Firmicutes, Clostridium coccoides, Clostridium leptum, B. fragilis and increased representation of Lactobacillaceae, Verrucomicrobiaceae, Ruminococcaceae, Lactobacuillus, Bacteroidetes, Proteobacteria, Clostridiaceae and Akkermansia (Hasegawa et al. 2015; Keshavarzian et al. 2015; Scheperjans et al. 2015). The increase in abundance of Lactobacillaceae could affect the ENS as these bacteria were found to increase the excitability of colonic after-hyperpolarization neurons by inhibiting calcium-dependent potassium channel opening (Kunze et al. 2009). Lactobacillus spp. quantity and serum leptin concentrations were found to be positively correlated (Queipo-Ortuno et al. 2013) while the decreased abundance of Prevotellaceae and increased abundance of Lactobacillaceae have been correlated with decreased levels of gut ghrelin. The latter hormone may regulate nigrostriatal dopamine function and restrict neurodegeneration in PD (Queipo-Ortuno et al. 2013; Scheperjans et al. 2015) and its secretion is decreased in PD patients (Unger et al. 2011). Although the diminished Prevotellaceae levels are not specific for PD and were reported in other diseases such as autistic spectrum disorders (Kang et al. 2013) or type 1 diabetes (Brown et al. 2011), increased fecal Prevotellaceae levels have been proposed as an excluding biomarker of PD (Scheperjans et al. 2015). Thus, the quantity of these bacteria was $77.6 \%$ lower in PD patients when compared to sex- and age-matched controls. Relative abundance of Prevotellaceae below $6.5 \%$ was found to be diagnostic of PD with $86.1 \%$ sensitivity and $38.9 \%$ specificity (Dinan and Cryan 2017). It was also reported that high levels of Enterobacteriaceae positively correlate with the severity of postural instability and gait difficulty (Scheperjans et al. 2015) supporting the existence of a link between gut microbiota composition and motor disturbances in PD.

Initial studies employing per os administration of hydrogen water in rats (Fu et al. 2009) and mice (Fujita et al. 2009) demonstrated its protective role in animal models of PD and a subsequent double-blind, randomized, controlled study in humans showed that $1000 \mathrm{ml}$ of hydrogen water per day improved the total Unified Parkinson's Disease Rating Scale scores (Yoritaka et al. 2013). Consequently, the hydrogen-producing bacteria were analyzed in PD patients. There was a decrease of six bacterial groups producing hydrogen: B. fragilis, C. perfringens, Pseudomonas spp., most strains in Enterobacteriaceae family, 12 species in Clostridium, $C$. coccoides group and C. leptum subgroup (Hasegawa et al. 2015).

Interestingly, small intestinal bacterial overgrowth was found to contribute to the pathophysiology of motor fluctuation in PD patients and eradication of bacterial overgrowth resulted in clinical improvement (Fasano et al. 2013), and it was also reported that patients with irritable bowel syndrome have an increased risk of developing PD (Lai et al. 2014). It has been proposed that gut microbiota in PD patients are shifted towards pro-inflammatory state, since certain genes related to the production of LPS and "pro-inflammatory" bacterial taxes like Akkermansia and Ralstonia were found to be increased in affected patients (Scheperjans 2016b).

Some authors also found an increase in gut permeability in patients with PD when using the urinary sucralose test (Julio-Pieper et al. 2014). This could results in passing of harmful substances into circulation (Forsyth et al. 2011).

\section{Conclusions}

There was a $90 \%$ decrease of plant fiber intake between 1800 and 1970, while the consumption of calories from animal fat and refined sugar increased four times in this time period (Burkitt et al. 1972). As the concentration of plant fiber in our diet fell below 20\% (Bengmark 2013), the GI transit time increased five-fold (Burkitt et al. 1972). These Western dietary habits caused a decrease both in absolute number and diversity of gut bacteria (Bengmark 2013).

There is ample evidence for the existence of communication between CNS, gut and intestinal microbiome (Rhee 
Table 1 Factors affecting the function of Central Nervous System (diet, metabolites, hormones, immune modulators, which can be modified by gut microbiota) and gut microbiota disturbances in multiple sclerosis, Alzheimer's disease, Parkinson's disease

\begin{tabular}{|c|c|c|c|}
\hline & Multiple Sclerosis & Alzheimer's Disease & Parkinson's Disease \\
\hline $\begin{array}{l}\text { Factors affecting the function of } \\
\text { Central Nervous System } \\
\text { (diet, metabolites, hormones, immune } \\
\text { modulators, which can be modified } \\
\text { by gut microbiota) }\end{array}$ & $\begin{array}{ll}\Downarrow \quad \begin{array}{l}\text { Butyrate } \\
\text { (Faecalibacterium }\end{array} \\
\text { metabolite); } \\
\Downarrow \quad \begin{array}{l}\text { Lipid 654 } \\
\text { (Bacteroidetes } \\
\text { metabolite); }\end{array} \\
\\
\begin{array}{l}\text { Proinflammatory } \\
\text { cytokines in serum; }\end{array} \\
\text { CD4 } 4^{+} \mathrm{CD} 25^{+} \text {regulatory } \\
\text { T cells target brain and } \\
\text { spinal cord; } \\
\text { Toxins B and D } \\
\text { of C. perfringens; }\end{array}$ & $\begin{array}{ll}\Downarrow & \text { Anti-inflammatory IL-10 in serum; } \\
\Downarrow & \text { GABA- levels in CNS; } \\
\Downarrow & \text { BDNF- involved in neuronal development, } \\
\text { differentiation, synaptic plasticity in CNS; } \\
\Downarrow \quad \text { DHA ( } \omega-3 \text { PUFA important for brain } \\
\text { functioning); } \\
\Downarrow \quad \text { EFA- mediate brain functions and structures; } \\
\\
\text { - Proinflammatory cytokines } \\
\text { (IL-6, CXCL2, NLRP3, IL-1 }) \text {; } \\
\text { A } \beta \text { in the cerebral cortex and other brain regions; } \\
\text { LPS- immune responses; } \\
\text { LGS- increased permeability of BBB, } \\
\text { A } \beta \text { accumulation and inflammatory response; } \\
\text { High-fat/ high-calories diet; } \\
\text { Gluten, sugar- stimulate systemic inflammation; }\end{array}$ & $\begin{array}{l}\Downarrow \quad \begin{array}{l}\text { Ghrelin- regulation of nigrostriatal } \\
\text { dopamine function, inhibition of } \\
\text { neurodegeneration; }\end{array} \\
\text { Neuronal inclusions (LB, LN); } \\
\text {-synuclein- accumulation in ENS; } \\
\text { LPS in serum; } \\
\text { LGS- passing to lumen bacteria } \\
\text { and their metabolites; } \\
\text { Serum leptin; } \\
\text { Hydrogen production (protective } \\
\text { role against PD)- B. fragilis, C. } \\
\text { perfringens, Pseudomonas spp., } \\
\text { most strains in Enterobacteriaceae } \\
\text { family, } 12 \text { species in Clostridium, } \\
\text { C. coccoides group and C. leptum }\end{array}$ \\
\hline Gut microbiota disturbances & $\begin{array}{ll}\Downarrow & \text { Faecalibacterium } \\
\Downarrow & \text { E. rectale } \\
\Downarrow & \text { Corynebacterium } \\
\Downarrow & \text { Fusobacteria } \\
\Downarrow & \text { Bacteroides } \\
& \\
\text { - } & \text { Escherichia } \\
\text { - Shigella } \\
\text { - } \\
\text { - } & \text { Clostridium } \\
\end{array}$ & $\begin{array}{ll}\Downarrow & \text { E. rectale } \\
\Downarrow & \text { B. fragilis } \\
& \\
& \\
\text { - Escherichia } \\
\text { - Shigella } \\
\text { - Shlamydia pneumoniae } \\
\text { - } \text { pallidum) } \\
\text { Helicobacter pylori }\end{array}$ & $\begin{array}{ll}\Downarrow & \text { Prevotellaceae } \\
\Downarrow & \text { Coprococcus } \\
\Downarrow & \text { Firmicutes } \\
\Downarrow & \text { Bacteroides fragilis } \\
& \\
- & \text { Lactobacilli } \\
- & \text { Verrucomicrobiaceae } \\
- & \text { Ruminococcaceae } \\
- & \text { Proteobacteria } \\
- & \text { Clostridiaceae } \\
- & \text { Akkermansia } \\
- & \text { Enterobacteriaceae } \\
- & \text { Helicobacter pylori }\end{array}$ \\
\hline
\end{tabular}

GABA gamma-aminobutyric acid, $B D N F$ brain-derived neurotrophic factor, $D H A$ docosahexaenoic acid, $\omega-3$ PUFA omega 3 polyunsaturated fatty acids, $E F A$ essential fatty acids, $A \beta$ amyloid- $\beta, L P S$ lipopolysaccharides, $L G S$ leaky gut syndrome; $C N S$ central nervous system, $L B$ Lewy bodies, $L N$ Lewy neuritis, ENS enteric nervous system, $P D$ Parkinson's disease

et al. 2009) and analysis of relationships between gut microbiota composition and CNS disorders has become a novel and promising field of research, which could provide understanding of disease pathogenesis and offer new and effective treatment options (Table 1) (Julio-Pieper et al. 2014; Luna and Foster 2015; Scheperjans 2016b). Future clinical studies of microbiota manipulations should be based on randomised, controlled trials.

\section{Compliance with ethical standards}

Conflict of interest The authors declare no conflict of interests.

Open Access This article is distributed under the terms of the Creative Commons Attribution 4.0 International License (http://creativecommons.org/licenses/by/4.0/), which permits unrestricted use, distribution, and reproduction in any medium, provided you give appropriate credit to the original author(s) and the source, provide a link to the Creative Commons license, and indicate if changes were made.

\section{References}

Adamczyk-Sowa M, Medrek A et al (2017) Does the gut microbiota influence immunity and inflammation in multiple sclerosis pathophysiology? J Immunol Res 2017:7904821
Adams-Carr KL, Bestwick JP et al (2016) Constipation preceding Parkinson's disease: a systematic review and meta-analysis. J Neurol Neurosurg Psychiatry 87:710-716

Alzheimer's Association (2015) 2015 Alzheimer's disease facts and figures. Alzheimers Dement 11:332-384

Archer T, Kostrzewa RM, Beninger RJ et al (2011) Staging neurodegenerative disorders: structural, regional, biomarker, and functional progressions. Neurotox Res 19:211-234

Asti A, Gioglio L (2014) Can a bacterial endotoxin be a key factor in the kinetics of amyloid fibril formation? J Alzheimers Dis 39:169-179

Atarashi K, Tanoue T, Shima T et al (2011) Induction of colonic regulatory $\mathrm{T}$ cells by indigenous Clostridium species. Science 331:337-341

Balin BJ, Gerard HC, Arking EJ et al (1998) Identification and localization of Chlamydia pneumoniae in the Alzheimer's brain. Med Microbiol Immunol 187:23-42

Barnett MH, Parratt JD, Cho ES et al (2009) Immunoglobulins and complement in postmortem multiple sclerosis tissue. Ann Neurol 65:32-46

Barrett E, Ross RP, O’Toole PW et al (2012) gamma-Aminobutyric acid production by culturable bacteria from the human intestine. J Appl Microbiol 113:411-417

Bekkering P, Jafri I, van Overveld FJ et al (2013) The intricate association between gut microbiota and development of type 1, type 2 and type 3 diabetes. Expert Rev Clin Immunol 9:1031-1041

Bengmark S (2007) Advanced glycation and lipoxidation end productsamplifiers of inflammation: the role of food. JPEN J Parenter Enteral Nutr 31:430-440

Bengmark S (2013) Gut microbiota, immune development and function. Pharmacol Res 69:87-113

Braak H, Del Tredici K (2008) Invited article: nervous system pathology in sporadic Parkinson disease. Neurology 70:1916-1925 
Bravo JA, Forsythe P, Chew MV et al (2011) Ingestion of Lactobacillus strain regulates emotional behavior and central GABA receptor expression in a mouse via the vagus nerve. Proc Natl Acad Sci USA 108:16050-16055

Bravo JA, Julio-Pieper M, Forsythe P et al (2012) Communication between gastrointestinal bacteria and the nervous system. Curr Opin Pharmacol 12:667-672

Brown DR (2016) Catecholamine-directed epithelial cell interactions with bacteria in the intestinal mucosa. Adv Exp Med Biol 874:79-99

Brown CT, Davis-Richardson AG, Giongo A et al (2011) Gut microbiome metagenomics analysis suggests a functional model for the development of autoimmunity for type 1 diabetes. PLoS One 6:e25792

Burkitt DP, Walker AR, Painter NS (1972) Effect of dietary fibre on stools and the transit-times, and its role in the causation of disease. Lancet 2:1408-1412

Cantarel BL, Waubant E, Chehoud C et al (2015) Gut microbiota in multiple sclerosis: possible influence of immunomodulators. $\mathrm{J}$ Investig Med 63:729-734

Carlino D, De Vanna M, Tongiorgi E (2013) Is altered BDNF biosynthesis a general feature in patients with cognitive dysfunctions? Neuroscientist 19:345-353

Cattaneo A, Cattane N, Galluzzi S et al (2017) Association of brain amyloidosis with pro-inflammatory gut bacterial taxa and peripheral inflammation markers in cognitively impaired elderly. Neurobiol Aging 49:60-68

Collins SM, Surette M, Bercik P (2012) The interplay between the intestinal microbiota and the brain. Nat Rev Microbiol 10:735-742

Daulatzai MA (2014) Role of stress, depression, and aging in cognitive decline and Alzheimer's disease. Curr Top Behav Neurosci 18:265-296

Diaz Heijtz R, Wang S, Anuar F et al (2011) Normal gut microbiota modulates brain development and behavior. Proc Natl Acad Sci USA 108:3047-3052

Dinan TG, Cryan JF (2012) Regulation of the stress response by the gut microbiota: implications for psychoneuroendocrinology. Psychoneuroendocrinology 37:1369-1378

Dinan TG, Cryan JF (2017) Gut feelings on Parkinson's and depression. Cerebrum pii: cer-04-17 (eCollection 2017)

Dinan TG, Borre YE, Cryan JF (2014) Genomics of schizophrenia: time to consider the gut microbiome? Mol Psychiatry 19:1252-1257

Eckburg PB, Bik EM et al (2005) Diversity of the human intestinal microbial flora. Science 308:1635-1638

Eskelinen MH, Ngandu T, Helkala EL et al (2008) Fat intake at midlife and cognitive impairment later in life: a populationbased CAIDE study. Int J Geriatr Psychiatry 23:741-747

Eskelinen MH, Ngandu T, Tuomilehto J et al (2009) Midlife coffee and tea drinking and the risk of late-life dementia: a population-based CAIDE study. J Alzheimers Dis 16:85-91

Evrensel A, Ceylan ME (2016) Fecal microbiota transplantation and its usage in neuropsychiatric disorders. Clin Psychopharmacol Neurosci 14:231-237

Farhadi A, Banan A, Fields J et al (2003) Intestinal barrier: an interface between health and disease. J Gastroenterol Hepatol 18:479-497

Farrokhi V, Nemati R, Nichols FC et al (2013) Bacterial lipodipeptide, lipid 654, is a microbiome-associated biomarker for multiple sclerosis. Clin Transl Immunology 2:e8

Fasano A, Bove F, Gabrielli M et al (2013) The role of small intestinal bacterial overgrowth in Parkinson's disease. Mov Disord 28:1241-1249
Fennessey CM, Sheng J, Rubin DH et al (2012) Oligomerization of Clostridium perfringens epsilon toxin is dependent upon caveolins 1 and 2. PLoS One 7:e46866

Fond G, Boukouaci W, Chevalier G et al (2015) The "psychomicrobiotic": targeting microbiota in major psychiatric disorders: a systematic review. Pathol Biol 63:35-42

Forbes JD, Van Domselaar G, Bernstein CN (2016) The gut microbiota in immune-mediated inflammatory diseases. Front Microbiol $7: 1081$

Forsyth CB, Shannon KM, Kordower JH et al (2011) Increased intestinal permeability correlates with sigmoid mucosa alpha-synuclein staining and endotoxin exposure markers in early Parkinson's disease. PLoS One 6:e28032

Foster JA, McVey Neufeld KA (2013) Gut-brain axis: how the microbiome influences anxiety and depression. Trends Neurosci 36:305-312

Fox M, Knapp LA, Andrews PW et al (2013) Hygiene and the world distribution of Alzheimer's disease: epidemiological evidence for a relationship between microbial environment and age-adjusted disease burden. Evol Med Public Health 2013:173-186

Friedland RP (2015) Mechanisms of molecular mimicry involving the microbiota in neurodegeneration. J Alzheimers Dis 45:349-362

Fu Y, Ito M, Fujita Y et al (2009) Molecular hydrogen is protective against 6-hydroxydopamine-induced nigrostriatal degeneration in a rat model of Parkinson's disease. Neurosci Lett 453:81-85

Fujita K, Seike T, Yutsudo N et al (2009) Hydrogen in drinking water reduces dopaminergic neuronal loss in the 1-methyl-4-phenyl1,2,3,6-tetrahydropyridine mouse model of Parkinson's disease. PLoS One 4:e7247

Gallagher DA, Lees AJ, Schrag A (2010) What are the most important nonmotor symptoms in patients with Parkinson's disease and are we missing them? Mov Disord 25:2493-2500

Gill HS, Rutherfurd KJ, Cross ML et al (2001) Enhancement of immunity in the elderly by dietary supplementation with the probiotic Bifidobacterium lactis HNO19. Am J Clin Nutr 74:833-839

Granieri E, Casetta I, Govoni V et al (2000) The increasing incidence and prevalence of MS in a Sardinian province. Neurology 55:842-848

Gu Y, Nieves JW, Stern Y et al (2010) Food combination and Alzheimer disease risk: a protective diet. Arch Neurol 67:699-706

Guarner F, Malagelada JR (2003) Gut flora in health and disease. Lancet 361:512-519

Haq S, Grondin J, Banskota S et al (2019) Autophagy: roles in intestinal mucosal homeostasis and inflammation. J Biomed Sci 26:19

Hasegawa S, Goto S, Tsuji H et al (2015) Intestinal dysbiosis and lowered serum lipopolysaccharide-binding protein in Parkinson's disease. PLoS One 10:e0142164

Haussner F, Chakraborty S, Halbgebauer R et al (2019) Challenge to the intestinal mucosa during sepsis. Front Immunol 10:891

Hill JM, Lukiw WJ (2015) Microbial-generated amyloids and Alzheimer's disease (AD). Front Aging Neurosci 7:9

Hobson P, Meara J, Ishihara-Paul L (2010) The estimated life expectancy in a community cohort of Parkinson's disease patients with and without dementia, compared with the UK population. J Neurol Neurosurg Psychiatry 81:1093-1098

Hu X, Wang T, Jin F (2016) Alzheimer's disease and gut microbiota. Sci China Life Sci 59:1006-1023

Hughes TF, Andel R, Small BJ et al (2010) Midlife fruit and vegetable consumption and risk of dementia in later life in Swedish twins. Am J Geriatr Psychiatry 18:413-420

Jaeger LB, Dohgu S, Sultana R et al (2009) Lipopolysaccharide alters the blood-brain barrier transport of amyloid beta protein: a mechanism for inflammation in the progression of Alzheimer's disease. Brain Behav Immun 23:507-517 
Jones MP, Dilley JB, Drossman D et al (2006) Brain-gut connections in functional GI disorders: anatomic and physiologic relationships. Neurogastroenterol Motil 18:91-103

Julio-Pieper M, Bravo JA, Aliaga E et al (2014) Review article: intestinal barrier dysfunction and central nervous system disorders-a controversial association. Aliment Pharmacol Ther 40:1187-1201

Kahn MS, Kranjac D, Alonzo CA et al (2012) Prolonged elevation in hippocampal Abeta and cognitive deficits following repeated endotoxin exposure in the mouse. Behav Brain Res 229:176-184

Kang DW, Park JG, Ilhan ZE et al (2013) Reduced incidence of Prevotella and other fermenters in intestinal microflora of autistic children. PLoS One 8:e68322

Katzenschlager R, Head J, Schrag A et al (2008) Fourteen-year final report of the randomized PDRG-UK trial comparing three initial treatments in PD. Neurology 71:474-480

Kau AL, Ahern PP, Griffin NW et al (2011) Human nutrition, the gut microbiome and the immune system. Nature 474:327-336

Keegan BM, Noseworthy JH (2002) Multiple sclerosis. Annu Rev Med 53:285-302

Keshavarzian A, Green SJ, Engen PA et al (2015) Colonic bacterial composition in Parkinson's disease. Mov Disord 30:1351-1360

Kleinewietfeld M, Manzel A, Titze J et al (2013) Sodium chloride drives autoimmune disease by the induction of pathogenic TH17 cells. Nature 496:518-522

Knight EM, Martins IV, Gümüsgöz S et al (2014) High-fat diet-induced memory impairment in triple-transgenic Alzheimer's disease (3xTgAD) mice is independent of changes in amyloid and tau pathology. Neurobiol Aging 35:1821-1832

Kowal SL, Dall TM, Chakrabarti R et al (2013) The current and projected economic burden of Parkinson's disease in the United States. Mov Disord 28:311-318

Kunze WA, Mao YK, Wang B et al (2009) Lactobacillus reuteri enhances excitability of colonic AH neurons by inhibiting calcium-dependent potassium channel opening. J Cell Mol Med 13:2261-2270

Kupsky WJ, Grimes MM, Sweeting J et al (1987) Parkinson's disease and megacolon: concentric hyaline inclusions (Lewy bodies) in enteric ganglion cells. Neurology 37:1253-1255

Kwon HK, Kim GC, Kim Y et al (2013) Amelioration of experimental autoimmune encephalomyelitis by probiotic mixture is mediated by a shift in $\mathrm{T}$ helper cell immune response. Clin Immunol 146:217-227

Lai SW, Liao KF, Lin CL et al (2014) Irritable bowel syndrome correlates with increased risk of Parkinson's disease in Taiwan. Eur J Epidemiol 29:57-62

Lanctot KL, Herrmann N, Mazzotta P et al (2004) GABAergic function in Alzheimer's disease: evidence for dysfunction and potential as a therapeutic target for the treatment of behavioural and psychological symptoms of dementia. Can J Psychiatry 49:439-453

Laske C, Stransky E, Leyhe T et al (2006) Stage-dependent BDNF serum concentrations in Alzheimer's disease. J Neural Transm 113:1217-1224

Lavasani S, Dzhambazov B, Nouri M et al (2010) A novel probiotic mixture exerts a therapeutic effect on experimental autoimmune encephalomyelitis mediated by IL-10 producing regulatory T cells. PLoS One 5:e9009

Lebouvier T, Chaumette T, Damier P et al (2008) Pathological lesions in colonic biopsies during Parkinson's disease. Gut 57:1741-1743

Lebouvier T, Neunlist M, Bruley des Varannes S et al (2010) Colonic biopsies to assess the neuropathology of Parkinson's disease and its relationship with symptoms. PLoS One 5:e12728

Lees AJ, Hardy J, Revesz T (2009) Parkinson's disease. Lancet 373:2055-2066
Luna RA, Foster JA (2015) Gut brain axis: diet microbiota interactions and implications for modulation of anxiety and depression. Curr Opin Biotechnol 32:35-41

Machiels K, Joossens M, Sabino J et al (2014) A decrease of the butyrate-producing species Roseburia hominis and Faecalibacterium prausnitzii defines dysbiosis in patients with ulcerative colitis. Gut 63:1275-1283

Maes M, Kubera M, Leunis JC et al (2012) Increased IgA and IgM responses against gut commensals in chronic depression: further evidence for increased bacterial translocation or leaky gut. J Affect Disord 141:55-62

Mager I, Roberts TC, Wood MJ et al (2014) From gut to brain: bioencapsulated therapeutic protein reduces amyloid load upon oral delivery. Mol Ther 22:485-486

Malaguarnera M, Bella R, Alagona G et al (2004) Helicobacter pylori and Alzheimer's disease: a possible link. Eur J Intern Med $15: 381-386$

Mancuso C, Santangelo R (2018) Alzheimer's disease and gut microbiota modifications: the long way between preclinical studies and clinical evidence. Pharmacol Res 129:329-336

Marras C, Lang A (2008) Invited article: changing concepts in Parkinson disease: moving beyond the decade of the brain. Neurology 70:1996-2003

Mayer EA (2000) The neurobiology of stress and gastrointestinal disease. Gut 47:861-869

Mazmanian SK, Round JL, Kasper DL (2008) A microbial symbiosis factor prevents intestinal inflammatory disease. Nature 453:620-625

Michalski B, Fahnestock M (2003) Pro-brain-derived neurotrophic factor is decreased in parietal cortex in Alzheimer's disease. Brain Res Mol Brain Res 111:148-154

Miklossy J (2011) Emerging roles of pathogens in Alzheimer disease. Expert Rev Mol Med 13:e30

Miyake S, Kim S, Suda W et al (2015) Dysbiosis in the gut microbiota of patients with multiple sclerosis, with a striking depletion of species belonging to clostridia XIVa and IV clusters. PLoS One 10:e0137429

Morris MC, Evans DA, Bienias JL et al (2003) Consumption of fish and n-3 fatty acids and risk of incident Alzheimer disease. Arch Neurol 60:940-946

Murrell TG, O’Donoghue PJ, Ellis T (1986) A review of the sheepmultiple sclerosis connection. Med Hypotheses 19:27-39

Nagahama M, Sakurai J (1992) High-affinity binding of Clostridium perfringens epsilon-toxin to rat brain. Infect Immun 60:1237-1240

Nieto R, Kukuljan M, Silva H (2013) BDNF and schizophrenia: from neurodevelopment to neuronal plasticity, learning, and memory. Front Psychiatry 4:45

Nuechterlein KH, Subotnik KL, Green MF et al (2011) Neurocognitive predictors of work outcome in recent-onset schizophrenia Schizophr Bull 37(Suppl 2):S33-S40

Ochoa-Reparaz J, Mielcarz DW, Ditrio LE et al (2009) Role of gut commensal microflora in the development of experimental autoimmune encephalomyelitis. J Immunol 183:6041-6050

Pistollato F, Sumalla Cano S, Elio I et al (2016) Role of gut microbiota and nutrients in amyloid formation and pathogenesis of Alzheimer disease. Nutr Rev 74:624-634

Postuma RB, Aarsland D, Barone P et al (2012) Identifying prodromal Parkinson's disease: pre-motor disorders in Parkinson's disease. Mov Disord 27:617-626

Prince M, Bryce R, Albanese E et al (2013) The global prevalence of dementia: a systematic review and metaanalysis. Alzheimers Dement 9:63-75.e2

Quadri P, Fragiacomo C, Pezzati R et al (2004) Homocysteine, folate, and vitamin B-12 in mild cognitive impairment, Alzheimer disease, and vascular dementia. Am J Clin Nutr 80:114-122 
Qualman SJ, Haupt HM, Yang P et al (1984) Esophageal Lewy bodies associated with ganglion cell loss in achalasia. Similarity to Parkinson's disease. Gastroenterology 87:848-856

Queipo-Ortuno MI, Seoane LM, Murri M et al (2013) Gut microbiota composition in male rat models under different nutritional status and physical activity and its association with serum leptin and ghrelin levels. PLoS One 8:e65465

Rhee SH, Pothoulakis C, Mayer EA (2009) Principles and clinical implications of the brain-gut-enteric microbiota axis. Nat Rev Gastroenterol Hepatol 6:306-314

Riccio P, Rossano R (2015) Nutrition facts in multiple sclerosis. ASN Neuro 7:1759091414568185

Rincon D, Vaquero J, Hernando A et al (2014) Oral probiotic VSL\#3 attenuates the circulatory disturbances of patients with cirrhosis and ascites. Liver Int 34:1504-1512

Rodriguez M, Wootla B, Anderson G (2016) Multiple sclerosis, gut microbiota and permeability: role of tryptophan catabolites, depression and the driving down of local melatonin. Curr Pharm Des 22:6134-6141

Round JL, Mazmanian SK (2009) The gut microbiota shapes intestinal immune responses during health and disease. Nat Rev Immunol 9:313-323

Rumah KR, Linden J, Fischetti VA et al (2013) Isolation of Clostridium perfringens type $\mathrm{B}$ in an individual at first clinical presentation of multiple sclerosis provides clues for environmental triggers of the disease. PLoS One 8:e76359

Scheperjans F (2016a) Can microbiota research change our understanding of neurodegenerative diseases? Neurodegener Dis Manag $6: 81-85$

Scheperjans F (2016b) Gut microbiota, 1013 new pieces in the Parkinson's disease puzzle. Curr Opin Neurol 29:773-780

Scheperjans F, Aho V, Pereira P et al (2015) Gut microbiota are related to Parkinson's disease and clinical phenotype. Mov Disord 30:350-358

Scott KP, Gratz SW, Sheridan PO et al (2013) The influence of diet on the gut microbiota. Pharmacol Res 69:52-60

Tremlett H, Waubant E (2017) The multiple sclerosis microbiome? Ann Transl Med 5:53

Tremlett H, Fadrosh DW, Faruqi AA et al (2016a) Gut microbiota composition and relapse risk in pediatric MS: a pilot study. $\mathrm{J}$ Neurol Sci 363:153-157

Tremlett H, Fadrosh DW, Faruqi AA et al (2016b) Associations between the gut microbiota and host immune markers in pediatric multiple sclerosis and controls. BMC Neurol 16:182

Tremlett H, Fadrosh DW, Faruqi AA et al (2016c) Gut microbiota in early pediatric multiple sclerosis: a case-control study. Eur J Neurol 23:1308-1321

Tremlett H, Bauer KC, Appel-Cresswell S et al (2017) The gut microbiome in human neurological disease: a review. Ann Neurol $81: 369-382$
Tully AM, Roche HM, Doyle R et al (2003) Low serum cholesteryl ester-docosahexaenoic acid levels in Alzheimer's disease: a casecontrol study. Br J Nutr 89:483-489

Unger MM, Moller JC, Mankel K et al (2011) Postprandial ghrelin response is reduced in patients with Parkinson's disease and idiopathic REM sleep behaviour disorder: a peripheral biomarker for early Parkinson's disease? J Neurol 258:982-990

Uzal FA, Kelly WR, Morris WE et al (2004) The pathology of peracute experimental Clostridium perfringens type D enterotoxemia in sheep. J Vet Diagn Investig 16:403-411

Visanji NP, Marras C, Kern DS et al (2015) Colonic mucosal a-synuclein lacks specificity as a biomarker for Parkinson disease. Neurology 84:609-616

Wang IK, Wu YY, Yang YF et al (2015) The effect of probiotics on serum levels of cytokine and endotoxin in peritoneal dialysis patients: a randomised, double-blind, placebo-controlled trial. Benef Microbes 6:423-430

Wu GD, Chen J, Hoffmann C et al (2011) Linking long-term dietary patterns with gut microbial enterotypes. Science 334:105-108

$\mathrm{Xu}$ J, Mahowald MA, Ley RE et al (2007) Evolution of symbiotic bacteria in the distal human intestine. PLoS Biol 5:e156

Yasutake C, Kuroda K, Yanagawa T et al (2006) Serum BDNF, TNFalpha and IL-1beta levels in dementia patients: comparison between Alzheimer's disease and vascular dementia. Eur Arch Psychiatry Clin Neurosci 256:402-406

Yehuda S, Rabinovitz S, Carasso RL et al (2002) The role of polyunsaturated fatty acids in restoring the aging neuronal membrane. Neurobiol Aging 23:843-853

Yehuda S, Rabinovitz S, Mostofsky DI (2005) Essential fatty acids and the brain: from infancy to aging. Neurobiol Aging 26(Suppl 1):98-102

Yoritaka A, Takanashi M, Hirayama M et al (2013) Pilot study of $\mathrm{H}(2)$ therapy in Parkinson's disease: a randomized double-blind placebo-controlled trial. Mov Disord 28:836-839

Zhang R, Miller RG, Gascon R et al (2009) Circulating endotoxin and systemic immune activation in sporadic amyotrophic lateral sclerosis (sALS). J Neuroimmunol 206:121-124

Zhang J, Ke KF, Liu Z et al (2013) Th17 cell-mediated neuroinflammation is involved in neurodegeneration of abeta1-42-induced Alzheimer's disease model rats. PLoS ONE 8:e75786

Zhao Y, Lukiw WJ (2015) Microbiome-generated amyloid and potential impact on amyloidogenesis in Alzheimer's disease (AD). J Nat Sci 1:e138

Publisher's Note Springer Nature remains neutral with regard to jurisdictional claims in published maps and institutional affiliations. 